\title{
Circuit
}

Musiques contemporaines

\section{On Stockhausen's Kontakte (1959-60) for tape, piano and percussion}

\author{
A lecture/analysis by John Rea given at the University of
}

Toronto, march 1968

\section{Sur Kontakte de Stockhausen (1959-1960) pour bande, piano et percussions} Une conférence/analyse de 1968

\section{John Rea}

Volume 19, numéro 2, 2009

Stockhausen au Québec

URI : https://id.erudit.org/iderudit/037453ar

DOI : https://doi.org/10.7202/037453ar

Aller au sommaire du numéro

Éditeur(s)

Les Presses de l'Université de Montréal

ISSN

1183-1693 (imprimé)

1488-9692 (numérique)

Découvrir la revue

Citer cet article

Rea, J. (2009). On Stockhausen's Kontakte (1959-60) for tape, piano and percussion: A lecture/analysis by John Rea given at the University of Toronto, march 1968. Circuit, 19(2), 77-86. https://doi.org/10.7202/037453ar
Résumé de l'article

Conférence donnée par John Rea à l'Université de Toronto en mars 1968. L'auteur y analyse l'oeuvre sous différents angles : aspects conceptuels (temps d'interprétation, temps de réalisation, perception subjective du temps, caractéristiques du concept de Moment), organisation formelle, définition structurelle, paramètres spatiaux, interprétation, etc. Par ailleurs, l'auteur avait pu s'entretenir avec le pianiste David Tudor, interprète de la création de Kontakte, alors à Toronto pour participer à un happening connu sous le titre Reunion (5 mars 1968), organisé par John Cage, qui jouait aux échecs avec Marcel Duchamp sur un échiquier photo-sensible. 


\section{Documents}

\section{On Stockhausen's Kontakte (1959-60) for tape, piano and percussion.}

A LECTURE/ANALYSIS BY JOHN REA

GIVEN AT THE UNIVERSITY OF TORONTO, MARCH 1968

In 1968, composer John Rea was twenty-four years old, and studying composition at the Master's level at the University of Toronto. It was there that he became interested in Stockhausen's work for piano, percussion and tape, Kontakte. This recently published score was available at the U. of T. music library, thanks to the progressive 'buy everything' policy of the day which allowed it to acquire a collection of often surprising books on music, LPs, and scores, which arrived in the library soon after publication. Pianist David Tudor, who had premiered the piece and performed it many times around the world, was in Toronto to participate, on March 5, in the now famous Reunion performance, involving John Cage, Marcel Duchamp, Duchamp's wife Teeny, David Behrman, Gordon Mumma, Lowell Cross and Tudor. The performance, held at the Ryerson Theatre, had Duchamp and Cage compete in a chess match which triggered a multitude of sound events controlled by the other participants. ${ }^{1}$ Rea took advantage of Tudor's presence to interview him about
Kontakte, and soon thereafter, in March, gave the following lecture as part of a graduate seminar in the Faculty of Music. The following text, transcribed by Rea in 2009 from a manuscript written in pencil, stands as perhaps the first analysis of a piece by Stockhausen in Canada, and because of both its historical significance, as well as the original observations which the young Rea makes in it, the editorial board of Circuit decided to include it in this issue.

Jonathan Goldman

\section{Introduction}

Though it is unusual to begin an analysis by enumerating the obstacles one encountered along the way to completing the analysis, I shall do this simply because

1. [Ed. note] Cf. Lowell Cross, "Reunion: John Cage, Marcel Duchamp, Electronic Music and Chess," Leonardo Music Journal, vol. 9 , pp. $35-42$ 
they point to the enormously complex, in my opinion, character of Karlheinz Stockhausen.

I could have easily begun this analysis like any other musical analysis - however, Kontakte, and mostly all of the remaining works of Stockhausen that I know simply are not like any other music - perhaps I do not even need to say this. And besides, a simple analysis would overlook the more fascinating aspects of his music, which are in fact the obstacles!

In the two volumes of Stockhausen's Texte ${ }^{2}-$ an accomplishment in itself perhaps unparalleled even in past times - think of Quantz, or C.P.E Bach - I found, as passages were read to me from the German, a continuous stream of ideas and formulations now in philosophy, now in psychology, now in acoustics, now in technology, sometimes in music! I do not think I'm being cynical: Stockhausen feels competent to envelope himself in all of these areas. But, in recent years, and especially in an article from volume I of Perspectives of New Music, his acoustical and technological jargon has come under attack by physical scientists. ${ }^{3}$

Another less formidable, but no less problematic, obstacle was the 67-page introductory booklet in German that comes together in the 1960 WERGO recording [LP-60 009] of Kontakte. When I became aware of the fountain of information immediately at hand, I figured that the analysis would write itself. Instead, I was confronted with a horrible, a staggering amount of

\footnotetext{
2. Texte zur Musik (Dumont-Buchverlag, Cologne)

3. See John Backus, "Die Reihe - A Scientific Evaluation," Perspectives of New Music, vol. 1, no. 1 (Autumn 1962), pp. 160-171.
}

information consisting of plans, scales, notes, charts, graphs, results of spectral analyses, etc.! But the real teaser was this statement that appears almost at the end of the introductory notes - "Schemes are not part of my techniques. They are odious. I don't like them." While a few paragraphs earlier, he had finished telling me, quite proudly, almost arrogantly, that a 40-second section in the second of sixteen formal structures required seven days of finely typewritten pages to initiate the first work on Kontakte!

I almost get the feeling that he wrote Kontakte to defend his theories - or at least (and this is more plausible) to demonstrate his new revolutionary (a word which does not appear in his vocabulary) theories.

Another obstacle rests in the decision on my part to discover [and select] the important things to treat in a coherent discussion of all the words Stockhausen writes: the philosophy, the acoustics, the psychology, and the musical score (and, as I said, music is a word that appears infrequently).

My preliminary conclusion: they are inseparable from one another, and this is one reason I believe a bulk of the music since the Second World War has been untouchable for everyday, even ordinary music students, simple because the programmatic résumés are too long and esoteric. But if one can sticks after Stockhausen and the rest of those composer-writerauthors, and wades through all of the literature, one can just about follow, as I did, every trick up his sleeve, and as I discovered it's possible, as it was for me, to perceive his tricks, and to discover in Kontakte that just about everything he says works, does indeed work! 
And so as I begin this discussion, I'll tell you that I am going to follow, more or less, Stockhausen's thinking and writing process - sometimes philosophy, sometimes acoustics, psychology, technology and sometimes music! If I were to discuss each individually, we would all be swimming because they really do not stand up so powerfully all alone - but together...

\section{Concepts}

Experiment: play the first two Moments, in reverse order, separately, II, silence, then I. After playing, II =0:23.6 seconds, then I = 0:15.7 seconds, ask the question: Which of the two sections from the opening of Kontakte appears shorter than the other?

Whatever it proves, Stockhausen is concerned here in Kontakte - a word which means connection between not only the instrumentalists and the tape, but also between characteristically striking musical events, and when performed in the four-channel version, between events moving through space - he is concerned with TIME, performance time, work time (metronome), production time (weeks, months, etc.), subjective perception of time, temporal transformations, and what he calls, Moment Time [Momente].

Read excerpt from: Northrop Fyre, The Modern Century, 1967, Oxford

PERFORMANCE TIME: Because it incorporates tapes sounds that are continuous for the entire length of the work, Kontakte will always have the same performance time, 34 minutes and 31.8 seconds. For Stockhausen, therefore, the work time (metronome) and the performance time coincide (for the first time in history) perfectly. Or simply, it's as if he wanted to contrast Toscanini's version of Beethoven's Fifth with Otto Klemperer's version.

PRODUCTION TIME: Stockhausen worked for fourteen months on Kontakte, from January 1958 to May, 1959, together with the aid of Gottfried-Michael Koenig who did a spectral analysis of all of the percussion instruments, and with the aid of technician, Jaap Spek.

Both Gesang der Jünglinge and Kontakte had been planned, Stockhausen insists, with distinct and strict limits. However, they turned out to be 'open' works, since he worked right up to the day of the Kontakte premiere in Cologne, he had to stop even though more had been written and was to have been included. Due to his responsibilities, and being rushed, he simply was forced to add a 'finale'. Then using a little play on German words, he distinguishes between a Schluss and an Ende. That is, he created an ending (Schluss) for a performance, but not for the work. He asks one to listen to the last seven minutes and see if there is not a deceptive quality about it (starting at 27:45.5).

As late as April 1960, he added structure 14, then two more structures immediately at the beginning. The only conclusion the commentator, who wrote the 67-page booklet, can make is that Stockhausen is just another man, and truly fallible - and these are his very words.

SUBJECTIVE PERCEPTION OF TIME: The audience's first comments immediately following the premiere, Stockhausen recalled, went like this: "Oh no, no, 34 minutes was too long! I think 8 minutes would have been better!" Another person said: "There was too much sound 
- I was saturated, things went by too fast!" Another: "If I'm going to have to sit here that long, I would rather listen to Bruckner and not to electronic music!"

Stockhausen concluded that people perceive the passage of time differently and hear things differently too (he compares this with watching a motion picture sitting in the front row versus sitting three-quarters of the way back). The location of a listener's seat is important since the loudspeaker-configuration was stable, fixed. But what about those sitting next to speaker number 4 ? Or what if one is too far away?

Since there were too many people at the premiere, and it was hot and humid, Stockhausen determined that, for the second performance, comfortable seats and air conditioning would make the piece appear shorter. He was happy with the outcome, but concluded that now he had to try to control the entire environment - the composition itself, and the conditions especially at performance time. Too many elements had become interrelated and what he termed the 'relativity of perspective lengths' would come under his control. Things only appear to be slow or fast depending upon their context. Therefore, Stockhausen and Bruckner should not be placed together for comparison: the nature of a Bruckner work points to different Momente than are found in Stockhausen's Kontakte.

MOMENT TIME: Now I can return to this little experiment. The second example $[I=0: 15.7$ seconds $]$ appeared longer because of relative inactivity, and the first example [ $I I=0: 23.6$ seconds], shorter than the first, because of greater relative activity. However, the performance time of the first section is not longer than the second section: $I=0: 15.7$ seconds; $I I=0: 23.6$ seconds. Stockhausen even carries the idea of relativity one step further by saying that in the section II, the instrumentalists are fast but relatively slower than the taped activity. If you haven't guessed it already, what I've been calling sections in reality are Momente, or to be more precise part-moments.

For the sake of a definition, Moment signifies: a unity of form that one perceives with its personal and immutable characteristics, or every thought that can stand by itself. Obviously, this is a qualitative definition. Of course, duration is one of its characteristics. A part-moment exists when there is something recognizably different but where the main character remains the same. If one goes a step further, one or more qualities together (which still retain the main quality) become a moment-group, e.g., the unity of the first six moments up to 02:10.

MOMENT CHARACTERISTICS: Stockhausen singles out four important characteristics for a moment to exhibit, in addition to its role and function. More or less verbatim:4 "Each moment, in itself static or in process, is a personal [and/or divisible] central fact that is to exist for its own sake. The musical events do not have a precise course from a determined beginning to an inevitable end" (Texte, p. 200). (It is as if Northrop Frye had read Stockhausen.) "A moment is

4. An adaption of a translation by Henry Weinberg in "Letter from Italy," Perspectives of New Music, vol. 1, no. 1 (Autumn, 1962), pp. 192-196. 
not only the consequent of the preceding and the cause of the succeeding" (Texte, p. 250) "The concentration on 'now', where each 'now' [these could be part-moments], on the contrary, is incised...vertically through the horizontal notion of time [and each cut is just long enough] ending in that negation of time that I call eternity: [this semblance of timeless existence] does not begin at the very end of Time, but in each moment it must be attained." (Texte, p. 250) Obviously, in harbouring such thoughts, Stockhausen admits to having been called a reactionary, even a Romantic artist. In this respect, Northrop Frye would agree!

Up to this point, one can now understand the compositional approach to two other works of Stockhausen listed under the heading of Moment-Form works: Carré, for four orchestras and choruses; and Momente, for soprano, four choruses, and thirteen instruments.

\section{Discussion of particular Moments}

Of the total number of different combinations of conditions under which a moment may exist, there are eight, and Stockhausen describes six of these; I will discuss only five however.

\section{DIAGRAM 1.}

\begin{tabular}{|l|l|l|}
\hline Formal conditions: & Personal & Divisible \\
\hline Temporal conditions: & Static & Dynamic \\
\hline
\end{tabular}

\section{POSSIBLE COMBINATIONS:}

\begin{tabular}{|l|l|l|l|l|l|l|l|}
\hline 1 & 2 & 3 & 4 & 5 & 6 & 7 & 8 \\
\hline Personal & Personal & Divisible & Divisible & Pers + Div & Pers + Div & Personal & Divisible \\
\hline Static & Dynamic & Static & Dynamic & Static & Dynamic & Stat + Dyn & Stat + Dyn \\
\hline
\end{tabular}

- Play EXAMPLE ONE (score p. 9), duration o:03 seconds - Combination of Personal form and the Static condition at IV-b (at 7:23.6),

Personal: six(?) different tones put together without repetition in pitch, interval, distance of entrance, length, and tone mixtures. Similarly, of tone mixtures, same dynamics over entrances that are immediately forte, constant tone texture.

Static: he says, simply, no change in this structural parameter.

- Play EXAMPLE TWO (score p. 30), duration 0:04.5 seconds

- Combination of Personal form and Dynamic (in process) condition at XIII-C (at 26:58.6)

Personal: glissando stroke.

Dynamic: descending tone colour becomes clearer and dynamic level comes down then crescendos, with an amplitude modulation that accelerates. 
- Play EXAMPLE THREE (score p. 18-19), duration 0:05 seconds

- Combination of Divisible form and Static condition at IX-d (at 16:08.8 to 16:33.6)

Divisible: repetition of isolated points and short groups of different numbers of tones; two different tone colours repeated; repetition of single intervals and pitches although not necessarily sequential, all are included.

Static: above activity spread over medium durational length, and average distances of entrances and intensities; towards tendencies of direction.

- Play EXAMPLE FOUR (score p. 30), duration 0:42 seconds

- Combination of Divisible form and Dynamic condition at XIII-C (at 26:62.8 to $27: 45.5$ )

Divisible: repetition of point and distances of entry, lengths, statistical tones mixtures, manner of entries and accents.

Dynamic: exploding tone cluster. At greater distances, softer dynamic levels, continuous but irregular withdrawal of texture.

- Play EXAMPLE FIVE (score p. 18), duration o:07 seconds (includes Example Two with instruments, plus Example Three)

- Combination of both Personal and Divisible form under a Static condition at IX-C (at 16:01.2 to 16:08.2)

Personal: 8 different chords, with different frequencies, intervals, lengths, distances of entry united by a high tone.

Divisible: repetition of the same tone mixture repetition of the same number of tones in each chord, repetition of the kind of chord, and closely related dynamics.

Static: no direct tendency in this parameter, he says. (How could it be in combination if it does not exist?
Or is its absence important also? Stockhausen says nothing.)

Stockhausen concludes that he has successfully been able to effect transformations from the Personal to the Divisible form, and from the Static to Dynamic temporal conditions. We will pursue this concept of temporal transformation later in our discussion.

\section{Hardware}

(1) Pulse wave generator, (2) Level-control amplifier, (3) Amplifier, (4) 12 different filters, (5) Reverberation unit, EMT.140, No 108, (6) Ring modulator (7) Sine-, Square-wave generators, (8) Low-tone generator, (9) Difference-tone 'hummer', (10) Four-channel variablespeed tape recorder, (11) 3 other three-speed tape-recorders connected to a patch board, (12) 3 Terz-filters (band pass), (13) Hand-operated rotation table to be used with four microphones.

\section{Overall Formal Organization}

In the original sketches for Kontakte, Stockhausen claims the work was to consist of 18 large sections called Structures, designated with Roman numerals in the score. And each Structure was to be made up of 6 smaller sections called part-structures, designated with six letters from the alphabet, $A$ through $F$, next to the Roman numerals.

Almost immediately I was confronted with a number of inconsistencies because of this new plan for organization:

(1) If we go along with Stockhausen and believe that the work is in fact not finished, then we can account for the reason why only 16 structures appear in the score instead of 18 as he says should be there. 
(2) Since, as he says, that as late as April 27, 1960, he added Structure XIV, and then added two more Structures at the very beginning because he was dissatisfied with the opening character of the then First Structure (which now should be Structure Three on the score), we can conclude, perhaps, that at the premiere, thirteen or fourteen structures had been used. Looking at the score, Structure III could have been an opening gesture and it mildly resembles Structure I.

(3) An even greater problem exists in trying to equate Moment-groups with Structures. At first, I was convinced that Structure was in fact another name for Moment-group, and part-structures, the name for ordinary Moments. In other words, every moment would be labeled with a letter from the alphabet (A through F), and every Moment-group with Roman numerals. However, contradictory information about this aspect exists simultaneously in Stockhausen's book, Texte. For example:

(a) Stockhausen designates the first Moment-group as the unity of the first six moments, up to 02:10. When I looked at the score, the indication 02:10 is also the duration of the first Structure with its six part-structure divisions, A-F. My conclusion: a Moment-group equals a Structure.

(b) When I investigated another element of Kontakte called temporal transformation, I learned that Stockhausen designates the second Moment-group as having the duration from 02:10 to 07:08.5. TILT, I said to myself. The score reveals that this duration contains two Structures, numbers II and III. I gave up!

\section{My definition of Structure}

Not to be prosaic about this whole situation, I will attempt my own definition of Structure: it is a unity of form that Stockhausen says must be understood by compositional-technical logic, and not by metaphysics, especially in the electronic music part. It is a unity of form that is governed by the relative activity and inactivity of the parameters that permit sound to be transformed.

Obviously, the next question would be: What are the parameters? Let me try to explain. They are:

(1) a series of number scales determines the density of each Structure

(2) the numbers 1 to 6 , where $1=$ the smallest increment of change, and $6=$ the largest $(0=$ no change at all), determine the following six parameters: intensity, position, speed, form, instrument, and space (an example of the space parameter is given below.)

(3) each of the six increments of change may vary to many different degrees in any of the following 10 characteristics: points, group, collections, strokes, colour, dynamics, rotations, space connection position, speed, and length.

(4) other scales may generate other scales that are more complex.

\section{Snow job?}

All I can say is that one must see the booklet from the WERGO recording to believe it. Stockhausen also informs us that this determination for change of values only appears in Kontakte. (It is also called sound transformation!) 
I will give you a simple example for the parameter of Space. (If you're interested in other examples for intensity, position, speed, form, and instrument, and how each is effected by change in points, grouped, collections, strokes, etc., I refer you to that booklet.)

\section{Parameter of Space, an example}

Because there are, as Stockhausen says, only 7 different total loud-speaker configurations taking $2+2$ speakers in a rotation combination, and because for each of the four loud-speakers (here I do not include the parameter of position, which he does), there are 6 increments for the characteristic Space, the connection position (designated by small triangles on his chart) for any single sound event may exist, therefore, in 42 total different variations!

This attempt at determining possibilities reminds me of Xenakis' work in determining probabilities.

Naturally, all these numbers are entered into a number chart under its appropriate parameter and characteristic heading. The series (Reihe) of numbers then indicates the relative activity that determines a Structure, and the series is found by adding the changing rates for each category on the chart. The series with the highest changing calibration is the series with the highest activity(?). Space, of course, is one of the most active parameters.

Then, in another one of those inconsistencies of which I spoke earlier, Stockhausen says that, whereas the entire first Structure is the most quiet (inactive) of the whole composition, the $17^{\text {th }}$ Structure is also quiet (space is inactive while the instruments are very active).
The trouble is that there is no $17^{\text {th }}$ Structure, at least not on the score!

Generally speaking, however, we can say that each Structure consists of half noise, and half sound elements, and that they have been planned to indicate which group (instrumental or electronic) will dominate, and where they may be equal. The average length for each Structure is about 2:30 minutes; the longest is XIII at 05:58; the shortest is XIV at 0:22; and Structure X (05:25) contains the example of Temporal Transformation.

\section{Temporal Transformation}

Finally, we arrive at perhaps the most fascinating aspect of the entire work. Since the technique of temporal transformation is explained quite thoroughly in volume I, number 1, of Perspectives of New Music ("The Concept of Unity in Electronic Music" (pp. 39-48)), I will try to summarize the information and present it as simply as possible.

Since "we perceive a sound event as a homogeneous phenomenon rather that as a composite of the four separate properties" of timbre, pitch, intensity and duration, Stockhausen "considered the possibility of equating the unity of perception with an analogous unity in composition," treating these four elements in a new correlation. He deduced "that all difference of acoustic perception can be traced to differences in the temporal structure of sound waves. The speed of oscillation of the waves, the particular interval (equal, regular or irregular), their intensity and frequency with which the pulsations reach the ear enable the listener 
to distinguish difference in pitch, timbre, simultaneity, sound-mixtures, and noise."

Thus, employing a pulse-wave generator, Stockhausen recorded a succession of pulses that had a very low speed range of pulsation, between 1/16 second and 16 seconds; he then increased the speed until he arrived at the field of frequencies and colour he desired. With any appropriate increase of speed, sometimes by use of a tape-loop, he achieves constant pitch. Any variation in the original succession of pulses when accelerated, determines colour. However, Stockhausen does admit that to achieve desired colour, one simply experiments.

This procedure then is deemed a compositional technique, and it permits him to assume the concept of a Single, Unified Musical Time - all the perceptual categories such as colour, harmony and melody, meter and rhythm, dynamics, and form (as in movements of works), are regarded as corresponding to different components (or functions) of this Unified Time.

Read from Perspectives of New Music, then play the example at 16:45 to 18:26.5

Perhaps here, a rhetorical question: Can we perceive moments, structures, and temporal transformations? Should we try to? Or, do we just absorb and become saturated like ink blotters to all impressions?

In my mind, Stockhausen has made some remarkable insights into the area of time perception. However, the relation between velocity of activities and the given context was something already known in the field of experimental psychology. What is remarkable, I believe, is that Stockhausen would simply apply this concept (which he believed he discovered by accident). The success of the temporal transformations is indisputable. As far as moments are concerned, there may yet be further experiments (that is, other works besides Carré and Momente). However, it is of primary importance that the listener goes to hear Kontakte for different reasons and for different criteria than when listening to Beethoven. This quality of being enraptured - almost hypnotized - does not occur in Beethoven, no matter what Donald Tovey or Romain Rolland may say. In this respect, I believe moments do succeed; they virtually destroy progressive or developing time, as it is known in classical music.

\section{Performance Practice}

The first thing to notice is that both players play from the score. During some of the first rehearsals, three percussionists were used, but this proved ineffective. Then, improvisation was tried, and that also failed and had to be abandoned. Christoph Caskel, who also appears on a recording of Zyklus, ultimately played the part.

David Tudor, pianist, also played some percussion instruments (cymbals, cowbells, and wood chimes) as well as two gongs placed between himself and the percussionist, and these instruments were used by both. Stockhausen indicates the percussion instruments using symbols rather than writing their names. The piano techniques are not revolutionary: clusters, harmonics, extended register passages played very fast, and no 12-tone row! 
STOPWATCH ACCURACY: I do not believe that the players themselves used stopwatches because of a comment Tudor made to me four weeks ago, scratching his head and remarking that nine years ago is a long time to remember(!) and that, moreover, he was sick of the piece, having played it too much! ${ }^{5}$ Hearing the electronic music parts, he told me, was very difficult especially in the four-channel version, and in unusually large rooms. The two-channel version was much simpler but sometimes presented some problems too. This is also why, in the published score, precise instructions appear on speaker distribution, what kind of amplifiers to use, and when additional speakers (tuned softer than the main ones) should be employed, and also, what kinds of concert halls work best.

The 1963 performance on the Deutsche Grammophone Gesellschaft recording [LP-SLPM 138811] is only 6 seconds off with respect to score. I believe other

5. N.B. (2009): I asked David Tudor various questions that he very graciously answered while he unplugged equipment following his marathon performance at the Ryerson Theatre in Toronto on March 5, 1968. Entitled Reunion, this 4.5 hour event included John Cage, who conceived the work; Marcel Duchamp and his wife Alexina (Teeny); and composers David Behrman, Gordon Mumma, David Tudor as well as Lowell Cross (a graduate student at the University of Toronto then, and teaching assistant to Gustav Ciamaga in the electronic music course for which I wrote this analysis), who designed and constructed the electronic chessboard upon which Cage and the Duchamps had played. For the final hour, I was the only member of the audience remaining in the theatre, and I've always wondered since whether my presence had anything to do with the ultimate duration of the performance, as opposed to the reported fatigue of Marcel Duchamp! See Lowell Cross, "Reunion: John Cage, Marcel Duchamp, Electronic Music and Chess," in Leonardo Music Journal, Vol. 9, pp. 35-42, 1999. recordings and phonographs themselves may be somewhat inaccurate. Stockhausen is accurate with his timings on his score, or almost. He admits though that some Structures are accurate while others not, due to machine cue delays, etc.

POST SCRIPT: The music of Kontakte was employed in 1961 to accompany (if that's the proper word) a kind of play or happening written by Stockhausen himself that lasted almost two hours. There are photographs of David Tudor dressed up as a Harlequin ${ }^{6}$ of the Commedia dell'Arte, and samples from the staging directions appear in volume two of the Texte.

\section{Conclusion}

Now that I have come to the end, I believe that I've made a startling discovery. It seems as if Stockhausen - unlike other composers such as Boulez who some critics say appears to be obscure and verbose in his writings - has gone out of his way to make his music, especially Kontakte, intelligible to his audience. His Texte seem to reveal his every secret. Unlike my first impressions, he is not trying to be obscure or mystical, and he tells us everything, so much so that one almost drowns at the least display of his informative capacities.

Stravinsky, writing in his Poetics of Music, quotes the painter Raphael: "To understand is to equal." । believe Stockhausen has challenged a new generation of composers - perhaps us!

6. N.B (2009): Stockhausen wrote Harlequin for clarinet solo in 1975 for American clarinetist Suzanne Stephens. The score reveals details about dance movements notated together with the music. 